\title{
RESÍDUOS SÓLIDOS URBANOS E EDUCAÇÃO AMBIENTAL NO MUNICÍPIO DE PRESIDENTE PRUDENTE-SP
}

Mariana Pompei Pinheiro', Priscila Gomes ${ }^{1}$, Fernanda Ayumi Hara', Yeda Ruiz Maria².

${ }^{1}$ Discentes do Curso de Arquitetura e Urbanismo da Universidade do Oeste Paulista - UNOESTE. ${ }^{2}$ Docente do Curso de Arquitetura e Urbanismo, Tecnologia em Design de Interiores e Engenharia Ambiental e Sanitária da Universidade do Oeste Paulista - UNOESTE

\section{RESUMO}

A educação ambiental é um tema retratado com o intuito de informar o público sobre a importância do meio ambiente e da interferência humana sobre este. A questão dos resíduos sólidos e sua má gestão é uma das problemáticas abordadas quando tratamos das interferências negativas do homem sobre a natureza. Atualmente há veículos de comunicação que podem informar as pessoas sobre o tema, mas será que há uma real sensibilização daqueles que o utilizam? Nas escolas, a abordagem do assunto é realizada de forma que os alunos entendam a fundo a necessidade de compreender o meio ambiente e as formas com que a sociedade os influencia? Foi realizada uma análise sobre a questão da gestão ambiental dos resíduos sólidos em escolas públicas e particulares. A pesquisa foi realizada em duas escolas no município de Presidente Prudente, uma estadual e uma particular.

Palavras - chave: Educação Ambiental, Resíduos Sólidos, Políticas Públicas

\section{INTRODUÇÃO}

O resíduo sólido que deixa de ser tratado, reciclado e reaproveitado não resulta apenas no desperdício em grande escala de material e energia. Para Cerdeira (1999) provoca ainda a degradação do solo arável, de rios, da atmosfera e de lençóis de água subterrâneos e é também capaz de causar erosão e tragédias, pois os detritos acumulados em bueiros, valas, ruas e favelas impedem o curso natural das águas, causando o desabamento de habitações e o alagamento de bairros inteiros.

Portanto entende-se que o lixo é um indicador da qualidade de vida da sociedade. Quanto mais uma sociedade produz desperdícios sob a forma de resíduos sólidos, resíduos líquidos e gases tóxicos, pior será sua qualidade de vida, uma vez que o solo, a água e o ar dos quais depende para sobreviver estarão contaminados (REIS, 2001).

A incorporação do marco ecológico nas decisões econômicas e políticas implica reconhecer que as consequências ecológicas, do modo como a população utiliza os recursos do planeta, estão associadas ao modelo de desenvolvimento (JACOBI, 2005). O nosso atual modelo de desenvolvimento é predatório e não se preocupa com a possibilidade de esgotamento de matéria- 
prima, assim torna-se clara a necessidade de repensar as formas de consumo já que o planeta dá evidentes sinais de cansaço e esgotamento de algumas fontes (DIAS, et al., 2008).

A geração de resíduos apresenta um papel importante dentro da atual preocupação ambiental, que passou a ganhar maiores destaques na década de 1970, a partir das transformações no debate "meio ambiente - desenvolvimento" que passaram então a apontar a finitude no interior do modo de produção capitalista e seus impactos globais (JACOBI, 2005).

Desta forma uma necessidade emergente no cenário mundial que busca a alteração do modo como os resíduos são tratados e também a forma como a população em geral se relaciona e se posiciona diante desta situação vem se tornando crescente, evidenciando a necessidade de ações sensibilizadoras de cunho transformador.

Para Oliveira (2002) e Bucci (2002), a solução dos problemas que envolvem a geração, a coleta e disposição final dos resíduos sólidos urbanos dependem da criação de políticas públicas específicas, aqui compreendidas como programas de ação governamental que visam coordenar os meios à disposição do Estado e as atividades privadas para a realização de objetivos socialmente relevantes e politicamente determinados (BUCCI, 2006).

As mobilizações ambientais vinculadas às atividades educativas tornam-se uma possibilidade, já que a educação é uma ferramenta importante, se não essencial, para a eficiência e efetividade de qualquer programa que busque uma compreensão da realidade e alterações da postura e da forma como os indivíduos se relacionam com o meio, propostas em programas de sensibilização. Assim a educação ambiental surge de maneira atual e transversal como uma possibilidade de formação e transformação.

Diante da necessidade de se compreender a relação existente entre a população e as ações de educação ambiental sobre os resíduos sólidos urbanos, surge a elaboração desta proposta de pesquisa, a qual terá como objeto de estudo as escolas $\mathrm{X}$ e $\mathrm{Y}$, sendo elas respectivamente particular e estadual, no município de Presidente Pudente-SP.

\section{OBJETIVOS}

O objetivo geral desta pesquisa é realizar um levantamento das condições atuais da prática da educação ambiental em âmbito escolar no município de Presidente Prudente-SP.

Como objetivos específicos procurou-se: 
- Identificar a situação atual dos resíduos sólidos quanto à sua conceituação e descarte e reconhecer os diversos subsídios teóricos que buscam promover a implantação da educação ambiental nas escolas;

- Observar o processo de aplicação prática das propostas de educação ambiental fomentadas em tais subsídios através de leis e políticas públicas específicas;

- Averiguar o processo de desenvolvimento dos projetos educacionais das diferentes escolas através das visitas em campo;

- Identificar como e quais são as atitudes tomadas a fim de sensibilizar os estudantes, em ambas as instituições.

\section{METODOLOGIA}

A metodologia empregada nesta pesquisa apresentou 3 etapas de trabalho:

1a etapa - Inicialmente houve uma discussão sobre a problemática dos resíduos sólidos de modo a abordar e compreender todos os seus processos, desde seu procedimento de geração ligado ao crescente consumo da população humana; a classificação de lixo e resíduos sólidos e seu consequente possível local de descarte, como os lixões, aterros ou mesmo a reciclagem, ainda tão pouco explorada no país.

Abordamos ainda a ação das políticas públicas no que se refere à gestão da educação ambiental, além da própria gestão dos resíduos sólidos e como isso repercute dentro do nosso meio, seja de maneira positiva ou negativa.

2a etapa - Com o intuito de analisar na prática a implementação da educação ambiental em âmbito escolar averiguamos uma instituição de ensino estadual e outra particular, ambas localizadas em Presidente Prudente - SP, através de atividade em campo. Para efeito de análise observamos as dependências e os métodos de ensino das unidades escolares a fim de reconhecer a existência da educação ambiental, tanto em ordem educacional como física, tais como a implantação de lixeiras de separação dos resíduos, exposição de trabalhos ou materiais informativos sobre o assunto em questão.

3a etapa - Por fim, com as informações obtidas através do trabalho em campo e discussão teórica realizadas, procuramos traçar um paralelo entre a realidade das duas instituições de ensino visitadas e analisar quais os aspectos positivos e negativos de cada situação. 
Através das etapas elaboradas para o desenvolvimento desta pesquisa, procurou-se demonstrar a atual situação da prática da educação ambiental em sala de aula, ou seja, se a formação ambiental dos cidadãos no local em que este deveria ser prioritário ocorre de fato e qual a relevância que as instituições de ensino oferecem para o tema do meio ambiente e para as relações humanas com este, relações essas capazes de interferir de modo significativo sobre nosso meio.

\section{DISCUSSÃO}

A prática da educação ambiental, em especial em âmbito escolar, trata-se de um processo onde as pessoas aprendem e conhecem sobre o funcionamento do ambiente, qual a nossa relação com este, como o afetamos e como promovemos sua sustentabilidade (DIAS, 1992).

DIAS (1992) ressalta ainda que o recinto escolar e sua dinâmica seja um espaço privilegiado para a abordagem de tais atividades que propiciem essa reflexão, através de aulas e atividades de campo e ações orientadas em projetos que passem a desencadear um comprometimento pessoal com a proteção ambiental.

Para EFFTING (2007) a abordagem e assimilação de uma visão ideal sobre os resíduos sólidos - principalmente quanto ao seu descarte - tratados em sala de aula são de extrema importância, visto que uma vez os alunos sensibilizados, iniciativas fora do ambiente escolar podem ser fomentadas, ou seja, na escola o aluno adquire o conhecimento de sua responsabilidade sobre o meio em que se insere e quais as melhores ações para intervir de forma correta sobre este, e fora da sala de aula pode lhes dar sequência, atingindo tanto o bairro no qual a escola está inserida como a comunidade em que este estudante reside.

Para subsidiar a aplicação da educação ambiental nas escolas públicas brasileiras, várias leis foram criadas com esta finalidade. Cita-se como exemplo a Política Nacional de Educação Ambiental - PNEA (№ 9.795) sancionada em 27 de abril de 1999, que aborda a educação ambiental como componente essencial e permanente da educação nacional e que deve estar presente de forma articulada em todos os níveis e modalidades do processo educativo, em caráter formal ou não formal.

Conforme a lei n. 9.795, de 27 de abril de 1999 que dispõe sobre a educação ambiental, institui a Política Nacional de Educação Ambiental e dá outras providências, entende-se por educação ambiental não formal as ações e práticas educativas voltadas à sensibilização da 
coletividade sobre as questões ambientais e à sua organização e participação na defesa da qualidade do meio ambiente.

Quanto à educação ambiental em caráter formal entende-se como a aplicação da questão nas instituições de ensino, de modo a propiciar aos alunos uma compreensão essencial do meio em que se vive, dos problemas que estão interligados a ele e o papel do ser humano como agente responsável por suas modificações ao longo da história. Sua aplicação deve abordar a complexidade dos problemas ambientais e como consequência, estimular o desenvolvimento de senso crítico dos estudantes a fim de procurarem soluções para resolver tais problemas.

Para análise da implantação da educação ambiental no município de Presidente Prudente, foram analisadas duas escolas de diferentes métodos de ensino (pública/ privada), onde é visível a diferença no currículo escolar. Foi averiguado durante as visitas em campo às escolas o desenvolvimento dos projetos educacionais; a visão do professor e seu papel na aplicação da educação ambiental; se existe e como é feita a sensibilização do aluno com relação à questão dos resíduos sólidos e como isso é aplicado na prática.

Para efeito de análise, foi averiguada uma das escolas públicas de Presidente Prudente, na qual se verificou que a educação ambiental não é constantemente tratada em sala de aula segundo a percepção dos alunos.

Observou-se que a abordagem de temas ligados ao meio ambiente é dada de maneira superficial ao estudante, como por exemplo, em datas comemorativas específicas (Dia da árvore, meio ambiente, etc.) onde há a análise e exploração de certas atividades complementares, porém temas ainda distantes da conscientização que a educação ambiental de fato deveria sugerir.

Acrescenta-se ainda que mesmo através do material pedagógico disponibilizado pelo governo para o trabalho diário com os estudantes, os temas ligados à sensibilização ambiental são pouco explorados, cabendo ao professor a iniciativa de abordá-los e complementá-los segundo sua experiência e formação acadêmica.

Em análise às dependências da escola pública notou-se que não existe a preocupação com a separação do lixo segundo sua natureza de origem. No refeitório, por exemplo, os resíduos gerados após a preparação dos alimentos são descartados em um lixo comum.

Enquanto no local de venda de alimentos (cantina) o lixo orgânico é separado e alguns tipos de materiais com o plástico são destinados à prática da reciclagem. Contudo materiais que poderiam tomar o mesmo destino, como o vidro, também são jogados no lixo comum, misturandose aos outros dejetos. 
Ao longo do interior da escola, nas salas de aula e corredores são utilizadas lixeiras de uso comum e apenas nas áreas externas como no pátio e na área próxima à quadra poliesportiva há lixeiras de separação de resíduos, contudo são mal posicionadas e sinalizadas, além de seu uso não estar associado à conscientização feita em sala de aula.

Em análise a instituição de ensino privada da cidade, constatamos uma realidade contrária, com mais prática e incentivo à educação ambiental.

Nesta unidade educacional, constataram-se diversas ações voltadas à ênfase da implantação da educação ambiental, como a abordagem do tema durante todo o ano letivo de 2012, buscando praticar a interdisciplinaridade em sala de aula, realizando trabalhos e atividades complementares como peças lúdicas, excursões e visitas com o intuito de informar e promover uma consciência ambiental coerente aos alunos de todas as séries.

Observou-se ainda a implantação de lixeiras de coleta seletiva em quantidade e posicionamento adequados ao longo da escola, parte dessas voltadas aos alunos e outra aos funcionários, concretizando a teoria aplicada em sala de aula sobre a importância da coleta seletiva.

\section{CONSIDERAÇÕES FINAIS}

Em análise às duas instituições de ensino constata-se a notável diferença que ocorre em relação à aplicação da educação ambiental em sala de aula. Mesmo com os diversos recursos teóricos de incentivo à implantação da educação ambiental em seu projeto pedagógico, a escola pública analisada não concretiza as sensibilizações aos estudantes, cabendo muitas vezes ao professor a "opção" de citar ou não assuntos relacionados, ou seja, na prática a falta de incentivo aos alunos por meio da conscientização, aliada à falta de recursos como lixeiras e sinalização adequadas, contribuem para a formação de cidadãos totalmente desvinculados de qualquer responsabilidade ambiental.

Por outro lado, em decorrência da análise da escola privada da cidade, constatou-se que mesmo com a abordagem do tema em seu material pedagógico, ainda há resistência por parte dos alunos à adesão de ações ambientalmente corretas, como a questão da separação dos resíduos. A esta síntese cabe salientar que a educação ambiental deve ser implantada de todas as formas - em caráter formal ou não formal - e utilizar-se de todos os tipos de mídia e divulgação para que a população de maneira geral tenha acesso à informações importantes como a relevância da coleta seletiva já nos dias de hoje. 
A ausência da aplicação da educação ambiental nas escolas é uma problemática que deve ser trabalhada a fim de sensibilizar as ações dos próprios estudantes e dos cidadãos de modo geral, responsáveis, assim como toda a sociedade, pela utilização dos recursos naturais e seu consequente desgaste e do meio ambiente.

\section{REFERÊNCIAS}

BRASIL. Lei no 9.795, 27 de abril de 1999. Dispõe sobre a educação ambiental, institui a Política Nacional de Educação Ambiental e dá outras providências. Diário Oficial [da República Federativa do Brasil], Brasília, DF, Seção III, Art. 13.

BUCCI, M. P. D. (org.) Políticas públicas: reflexões sobre o conceito jurídico. São Paulo: Saraiva, 2006.

BUCCI, M. P. Direito administrativo e políticas públicas. São Paulo: Saraiva, 2002.

CERDEIRA Rizzo, C. P. A percepção do lixo na perspectiva de diferentes atores sociais no ambiente urbano de Paranaguá: Curitiba, UFPR (Tese de Doutorado), 1999.

DIAS, G. F. Educação Ambiental: princípios e práticas. Ed. Gaia. São Paulo, 1992.

DIAS, T. N.; SOBRAL, C. R. S.; CORREA, P. F. Sensibilização Ambiental e Implantação da Coleta Seletiva e Diferenciada no Bairro Matozinhos em SJDR, Colóquio Internacional Atividade e Afeto, Belo Horizonte, 2008.

EFFTING, T. R. Educação Ambiental nas Escolas Públicas: Realidade e Desafios. Monografia de Pós Graduação em "Latu Sensu" em Planejamento Para o Desenvolvimento Sustentável - Centro de Ciências Agrárias, Universidade Estadual do Oeste do Paraná - Campus de Marechal Cândido Rondon, 2007.

JACOBI, P. Educação Ambiental: o desafio da construção de um pensamento crítico, complexo e reflexivo. Universidade de São Paulo, 2005.

OLIVEIRA, A. S. D. de. Método para viabilização da implantação de plano de gerenciamento integrado de resíduos sólidos: o caso do município do Rio Grande-RS.: UFSC, Florianópolis/SC, 2002. (tese de doutorado).

REIS, H. L. Metodologia de Avaliação de Investimentos em Projetos Ambientais. Tese de Doutorado. Departamento de Engenharia de Produção. Escola Politécnica. USP, 2001. 